Stand structure and dynamics during a 16-year period in a sub-boreal conifer-hardwood mixed forest, northern Japan

Koichi Takahashi $^{\mathrm{a}, 1,{ }^{1,}, \text { Daisuke Mitsuishi }^{\mathrm{a}} \text {, Shigeru Uemura }}{ }^{\mathrm{b}}$, Jun-Ichirou Suzuki ${ }^{\mathrm{a}, 2}$, Toshihiko Hara ${ }^{\mathrm{a}}$

a: The Institute of Low Temperature Science, Hokkaido University, Sapporo 060-0819, Japan

b: Forest Research Station, Field Science Center for Northern Biosphere, Hokkaido University, Nayoro 096-0071, Japan

\title{
Present address
}

1: Department of Biology, Faculty of Science, Shinshu University, Matsumoto 390-8621, Japan

2: Department of Biology, Faculty of Science, Tokyo Metropolitan University, Tokyo 192-0397, Japan

*: All correspondence to K. Takahashi at the above present address\#1.

Fax: +81.263 .37 .2560$

E-mail: koichi@gipac.shinshu-u.ac.jp

This manuscript consists of 23-typed pages including figure legends, 3 tables and 6 figures. 


\section{Abstract}

The stand structure and regeneration dynamics of trees $>2.0 \mathrm{~m}$ in trunk height were studied during 1982-1998 in a 1-ha plot in a sub-boreal conifer-hardwood mixed forest, northern Japan, with a dense dwarf bamboo in the understory. Total density was low in 1982 (651 trees/ha), as compared with other forests in Japan. Quercus crispula was dominant in the upper canopy layer but their saplings were rare, while Acer mono, Acer japonicum and Abies sachalinensis were dominant in the sub-canopy and understory layers with many saplings. Mortality of each species was quite low during the census period (average $0.57 \% / \mathrm{yr}$ ), and there was no clear difference among the four species. The age structure of Quercus crispula was bell-shaped with a peak at ca. 200 years, while that of the other three species was weakly reverse-J shaped or a rough plateau. In addition, no recruits growing over a height of $2 \mathrm{~m}$ were observed during the census period in Quercus crispula, but many recruits of the other species were observed. These suggest that Quercus crispula depended on episodic disturbances for the persistence of its population. Recruits of the three species except for Quercus crispula did not concentrate in canopy gaps probably because of the dense dwarf bamboo cover there. They showed a negative spatial association with their own canopy trees, but a positive association with canopy trees of Quercus crispula. Most of the crowns of the three species (Abies sachalinensis and the two Acer spp.) were lower than that of overtopping Quercus crispula. These spatial associations between recruits and canopy trees brought about the competitive effect of Quercus crispula on the growth rates of other species and that of itself. However, the low mortality of trees taller than $2 \mathrm{~m}$ indicates that intra- and interspecific competition was not strong as a structuring force of the tree community. Our long-term study suggests that factors affecting recruitment (disturbances and dwarf bamboo in the forest floor) are more important for species coexistence than intra- and interspecific competition between trees taller than $2 \mathrm{~m}$.

Keywords: Community dynamics; Competition; Conifer-hardwood mixed forest; Long-term study; Permanent plot

\section{Introduction}

Conifer-hardwood mixed forests are widely distributed in the middle latitude of Northern Hemisphere (Tatewaki, 1958; Woods, 1984; Taylor and Qin, 1988; Ishikawa et al., 1999). Forest structure and dynamics of this type of forest ecosystem have often been examined in relation to disturbance regime (Ishikawa and Ito, 1989; Osawa, 1992). For example, several researchers have shown discontinuous age and size distributions and discussed the importance of major disturbances for species coexistence (Oliver and Stephens, 1977; Ishikawa and Ito, 1989; Yamamoto et al., 1995; Abrams and Orwig, 1996; Sano, 1997). Return times for major disturbances are unpredictable, and sometimes exceed more than a millennium (Lorimer, 1977; Canham and Loucks, 1984; Whitney, 1990). Although the importance of major disturbances on species coexistence is well recognized, our understanding of mechanisms of species coexistence during a period free from major disturbances is still limited.

Several researchers proposed a reciprocal replacement hypothesis for stable coexistence of species (Forcier, 1975; Fox, 1977; Runkle, 1981; Woods, 1984). For example, saplings of Acer saccharum and Fagus grandifolia recruited under the crowns of different species rather than under those of the same species in north America (Woods, 1984), resulting in the stable coexistence of dominant species by reciprocal 
replacement. Furthermore, the spatial pattern of recruits affects intra- and interspecific competition. Duncan $(1991,1993)$ showed that each of four podocarp species had a specific microhabitat for seedling establishment or recruitment, which caused spatial segregation between the four species. This spatial pattern brought about coexistence between the four species because of the avoidance of interspecific competition (Duncan, 1991, 1993). Therefore, the spatial association between new recruits and adult trees and the competitive process between species provide useful information to elucidate regeneration dynamics and mechanisms of species coexistence.

Long-term observation is of great importance for understanding forest dynamics and mechanisms of species coexistence because forest ecosystems are not stable in time and space in terms of size structure, species composition and spatial distribution of trees (Woods, 2000a, b). Measurements of recruitment rate, mortality and population growth rate provide useful information to analyze factors affecting population dynamics and species coexistence (Nakashizuka, 1991a). Recently, many long-term studies in various types of forest ecosystems have been published (Manokaran and Kochummen, 1987; Nakashizuka 1991b; Namikawa, 1996; Tsuyuzaki and Haruki, 1996; Bunyavejchewin, 1999; Umeki and Kikuzawa, 1999; Woods, 2000a, b). However, there have been few long-term studies that investigated the spatial distribution of recruits and competition, in relation to species coexistence.

Our long-term study examined mechanisms of species coexistence in a sub-boreal conifer-hardwood mixed forest with dense undergrowth bamboo in northern Japan, using 16-year data (1982-1998) of trees taller than $2 \mathrm{~m}$ in a 1-ha plot. First, we describe the structural change of this forest and population flux of the component species during the 16-year period. Second, we analyze the population structure and dynamics of dominant species based on size and age structure, spatial association between recruits (height of $2 \mathrm{~m}$ ) and trees (taller than $2 \mathrm{~m}$ ), and competition between trees. In particular, we attempted to answer the following questions:

(1) Is this forest stable in terms of species composition and size structure?

(2) How do canopy conditions (gap or closed, species of canopy trees) affect the spatial distribution of recruits?

(3) How does interspecific competition affect the population dynamics of dominant species?

\section{Study site}

Field study was carried out in a natural conifer-hardwood mixed forest in Uryu Experimental Forest of Hokkaido University $\left(44^{\circ} 20^{\prime} \mathrm{N}, 142^{\circ} 15^{\prime} \mathrm{E}, 380 \mathrm{~m}\right.$ above sea level) in Hokkaido, northern Japan. During 1961-1980, mean monthly temperatures in July and January were 17.9 and $-12.1^{\circ} \mathrm{C}$, respectively. Mean annual precipitation was 1573 $\mathrm{mm}$. Snow-cover season extends over half the year, and snow depth was ca. 2-3 m. Kira's warmth index (WI) has often been used in Japan to explain climatic zones and vegetation patterns along latitude and altitude (Kira, 1949; Ohsawa, 1995). WI is calculated as $\Sigma\left(m_{t}-5\right)$, where $m_{t}$ is mean monthly temperature above $5^{\circ} \mathrm{C}$. WI expresses the approximate effective heat for plant growth. WI in this study site was 44.6, representing a sub-boreal zone. The forest around this study site was dominated by deciduous broad-leaved species such as Quercus crispula, Acer mono, Betula ermanii, Kalopanax pictus, Tilia japonica and Acer japonicum and by conifers such as Abies sachalinensis and Picea glehnii. The forest floor was densely covered with dwarf bamboo Sasa senanensis. The canopy height of Sasa was ca. $2 \mathrm{~m}$, and the mean leaf area index of Sasa was $2.8 \mathrm{~m}^{2} / \mathrm{m}^{2}$. 


\section{Methods}

\subsection{Field measurements}

A 1-ha plot (100-m $\times 100-\mathrm{m})$ was established in 1982, and further divided into $4005-\mathrm{m} \times 5-\mathrm{m}$ quadrats. All trees taller than $2.0 \mathrm{~m}$ in trunk height were tagged and measured for $x-y$ coordinates, trunk diameter at breast height (DBH) and trunk height. In 1992 and 1998, DBH, trunk height and crown projection area were measured for all living trees taller than $2.0 \mathrm{~m}$. New trees growing over a height of $2 \mathrm{~m}$ during the successive censuses were recorded, and were defined as recruits. Dead trees during the successive censuses were also recorded in 1992 and 1998. Crown projection area was calculated based on the four lengths (NSWE) from the base of a trunk to the edge of the crown in 1992 and 1998. Wood cores were taken at $1.3 \mathrm{~m}$ in trunk height during 1997-1998 for all trees larger than $6.0 \mathrm{~cm}$ in DBH, and ring widths were read to the nearest $0.01 \mathrm{~mm}$ with a binocular.

\subsection{Data analysis}

\subsubsection{Spatial distribution}

In this paper, two life phases were defined: sapling (2.0-9.9 $\mathrm{m}$ in trunk height) and canopy tree (taller than $10.0 \mathrm{~m}$ in trunk height). The crown projection area of each canopy tree was drawn on a map, and we determined canopy gaps in each $5-\mathrm{m} \times 5-\mathrm{m}$ quadrat; quadrats with less than $50 \%$ of canopy coverage were defined as canopy gaps in this study. We focused on four dominant species, Quercus crispula, Abies sachalinensis, Acer mono and Acer japonicum, in this study. To examine the canopy-gap dependency of the spatial distribution of saplings (2.0-9.9 m tall) and recruits of the four species during 1982-1998, the observed and expected densities of gap and non-gap saplings (or recruits) were compared by the $\chi^{2}$-test. The expected number of gap saplings (or recruits) was calculated as the product of the gap area ratio (gap area/plot area) and the total observed number (gap plus non-gap) of saplings (or recruits). We used data in 1982 for saplings and data during 1982-1998 for recruits, because the sapling class includes recruits if we use data in 1998 for saplings. We could not define gap or non-gap for the outer quadrats of the 1-ha plot, because we did not measure the crown projection area of surrounding trees adjacent to the 1-ha plot. Therefore, we used the quadrats in the inner $80-\mathrm{m} \times 80-\mathrm{m}$ plot for the analysis of the gap-dependency of the spatial distributions of saplings and recruits.

The spatial association between saplings, recruits and canopy trees was analyzed by using Iwao's $\omega$ index (Iwao, 1977), which has often been used to analyze the spatial association between two populations (Kohyama et al., 1994; Yamamoto et al., 1995; Manabe and Yamamoto, 1997; Takahashi et al., 2001). This index is calculated by the following equations:

(1) $\omega_{(+)}=\frac{\gamma-\gamma_{(\text {ind })}}{1-\gamma_{(\text {ind })}}$ for $\gamma \geq \gamma_{\text {(ind) }}$

or

(2) $\omega_{(-)}=\frac{\gamma-\gamma_{(\text {ind })}}{\gamma_{(\text {ind })}}$ for $\gamma \leq \gamma_{(\text {ind })}$,

where 
(3) $\gamma=\sqrt{\left(\frac{m_{Y X}^{*}}{m_{X}} \cdot \frac{m_{X Y}^{*}}{m_{Y}}\right) /\left(\frac{m_{X}^{*}+1}{m_{X}} \cdot \frac{m_{Y}^{*}+1}{m_{Y}}\right)}$

and

(4) $\gamma_{\text {(ind) }}=\frac{1}{\sqrt{\frac{m_{X}^{*}+1}{m_{X}} \cdot \frac{m_{Y}^{*}+1}{m_{Y}}}}$,

where $m_{X}$ and $m_{X}^{*}$ (or $m_{Y}$ and $m^{*}$ ) are mean density and mean crowding of species $X$ (or species $Y$ ), respectively. Mean crowding on species $X$ by species $Y$ is denoted as $m_{X Y}^{*}$, and that on species $Y$ by species $X$ is denoted as $m^{*}{ }_{Y X}$. This index ranges from -1.0 to 1.0. $\omega$ equals 0 for mutually independent distributions, $\omega>0$ for positive association, and $\omega<0$ for negative association (see Iwao [1977] for more details). We examined the spatial association between canopy trees and saplings, between canopy trees and recruits and between saplings and recruits. We used data in 1982 for canopy trees and saplings and data in 1998 for recruits to avoid auto-correlation between saplings and recruits, i.e., saplings in 1982 do not include recruits in 1998. We used the quadrat size of $10-\mathrm{m} \times 10-\mathrm{m}$ for calculating $\omega$. We conducted a randomization test to determine significant differences in the observed $\omega$ from random distribution between saplings, recruits and canopy trees. The data sets of two layers as canopy trees and saplings (or recruits) were re-assorted randomly. We calculated $\omega$ for all the possible combinations of the two layers, i.e., 2 reflections $\times 4$ rotations $\times 10 x$-sifts $\times 10 y$-shifts of the canopy layer, keeping the spatial distribution of saplings (or recruits) fixed. The number of possible combinations was 800 . If the observed $\omega$ fell in either of the $5 \%$ tail of the calculated- $\omega$-distribution, the observed $\omega$ between the examined two layers was assumed to be significantly different from random.

\subsubsection{Intra- and interspecific competition}

We analyzed the effects of intra- and interspecific competition on the growth rate of DBH for the four dominant species, applying the following equation (cf. Hara et al., 1995; Kubota and Hara, 1995; Nakashizuka and Kohyama, 1995; Takahashi and Kohyama, 1999),

(5) $G_{k}(t, x)=x\left[a_{0}-a_{1} \ln x-\sum_{i=1}^{n} a_{2 i} C_{i}(t, x)\right]$,

where $G_{k}(t, x)$ is the absolute growth rate in $\mathrm{DBH}\left(\mathrm{yr}^{-1}\right)$ of species $k$ of size $x$ at time $t$, and $C_{i}(t, x)$ is the cumulative basal area $\left(\mathrm{cm}^{2} / \mathrm{m}^{2}\right)$ of neighboring trees of species $i$ larger than size $x$ at time $t$. Coefficient $a_{0}, a_{1}$ and $a_{2 i}$ are constants. Target individual trees were divided into five arbitrary DBH classes chosen to arrange similar vertical strata $(0-4.9,5.0-9.9,10.0-19.9,20.0-39.9$, over $40.0 \mathrm{~cm}$ in DBH). We defined the neighboring trees if they satisfied the following two conditions: trees belonging to the same or larger size class of the target individual tree, because primary interest of this analysis was to express competition for light; trees in the same $10-\mathrm{m} \times 10-\mathrm{m}$ quadrat in which the target tree was located. Hara et al. (1995) examined changes in $R^{2}$ of the $G_{k}$ $(t, x)$ function with varying neighborhood radius from the target tree in a cool-temperate forest in southwestern Japan, and found that the maximum $R^{2}$ was obtained at a radius of $5 \mathrm{~m}$ in most species examined. Therefore, the quadrat size of $10-\mathrm{m} \times 10-\mathrm{m}$ is 
appropriate as a neighborhood area when target trees are assumed to be at the center of a $10-\mathrm{m} \times 10-\mathrm{m}$ quadrat. This definition of neighborhood area sometimes brings about a crude measure of local crowding if target trees are near the edge of a quadrat, i.e., a target tree near the edge of a quadrat will be affected by trees at the adjacent quadrat but not much by trees at the other end of the same quadrat. However, the number of $10-\mathrm{m}$ $\times 10$-m quadrats used in this analysis was 100 in total, which could include a large variation in local crowding from canopy-gap conditions to entire closed-canopy conditions. In addition, the results are comparable with other studies because this definition of neighborhood area has often been adopted (cf. Kohyama 1992, 1993, Kubota and Hara 1995, Nakashizuka and Kohyama 1995, Takahashi and Kohyama 1999). We also performed the spatial competition analysis, considering distant-dependent competitive effects of neighbors, like Hara et al. (1995), and we obtained the same results as this non-spatial competitive analysis described by the equation 5. Therefore, for simplicity, the non-spatial analysis was conducted in this study, using with the neighborhood area of 10-m $\times 10-\mathrm{m}$.

Cumulative basal area of neighboring trees of each species [i.e., $\sum C_{i}(t, x)$ ], was calculated for each target individual tree. In this study, the species other than the four dominant species were treated as "one species" for the calculation of $C_{i}(t, x)$.

Multiple linear regression analysis was conducted for $G_{k}(t, x) / x$ (i.e., relative growth rate) for each species. The forward stepwise method was used to remove and to enter explanatory variables. This study set the $P$-value to enter at 0.05 and that to remove at 0.10 (Sokal and Rohlf, 1995). The dependent and independent variables were ln-transformed, if necessary, before statistical analysis to improve homoscedasticity. Residual analyses were also performed, and extreme outliers were excluded.

\section{Results}

\subsection{Changes in tree density and basal area during 16 years}

In total, 17 and 18 species ( $>2.0 \mathrm{~m}$ tall) appeared within this 1-ha plot in 1982 and 1998, respectively. This forest was dominated by the four species (Acer mono, Abies sachalinensis, Quercus crispula and Acer japonicum), and these four species accounted for ca. $74 \%$ of the total density in both years, 1982 and 1998 (Table 1). Acer mono, Abies sachalinensis and Quercus crispula are canopy species, while Acer japonicum is an understory species. In terms of basal area, Quercus crispula occupied ca. $67 \%$ of the total basal area in both years, and the basal area of the other species was less than $15 \%$ (Table 1). Total tree density ( $>2.0 \mathrm{~m}$ tall) increased from 651 to 758 trees/ha during 1982-1998 (Table 1). Recruitment rate and mortality in total were 1.59 and $0.57 \% / y r$, respectively. Recruitment rate exceeded mortality for all the species except for Quercus crispula that had no recruits (Table 1). Recruitment rate was negatively correlated with the observed maximum DBH of each species (Pearson correlation coefficient $R=-0.88, P<0.001, n=10$, Fig. 1). This tendency was persistent even if Quercus crispula and Viburnum furcatum were excluded $(R=-0.77, P$ $<0.05, n=8)$. Total basal area increased from 36.79 to $40.79 \mathrm{~m}^{2} /$ ha during this period (Table 1$)$. The loss of basal area by death $(0.30 \% / y r)$ was ca. one-third of the gain by growth of surviving trees $(0.95 \% / \mathrm{yr})$. Most of the species showed a positive balance of basal area (Table 1). Acer japonicum lost the greatest amount of basal area among the component species because the largest tree died. The coverage of canopy gaps was $23.3 \%$ in 1992 . $15.3 \%$ of the examined area changed from gaps to closed canopy during 1992-1998, while 5.0\% changed from closed canopy to canopy gaps. As a consequence, the canopy-gap percentage decreased from $23.3 \%$ to $13.3 \%$ during this 
period.

\subsection{Species population dynamics}

This study focused on the four dominant species, Quercus crispula, Abies sachalinensis, Acer mono and Acer japonicum (Table 1). The frequency distribution of DBH of Quercus crispula was bell-shaped with a peak at $55 \mathrm{~cm}$ in 1998, while the three species other than Quercus crispula showed reverse-J shaped distribution (Fig. 2). The frequency distribution of tree height of each species was similar to that of DBH (Fig. 3): Quercus crispula showed a bell-shape with a peak at $23 \mathrm{~m}$, and the maximum height was $24.5 \mathrm{~m}$, while most of the other three species were shorter than $10 \mathrm{~m}$. Tree age of Quercus crispula (>6.0 cm in DBH) was concentrated at around 200 years, and $73 \%$ of them were between 180-220 years (Fig. 4). In contrast, tree-age distribution of the other three species was weakly reverse-J shaped or a rough plateau (Fig. 4). The maximum tree age of the three canopy species was 446 years for Quercus crispula, 178 years for Abies sachalinensis and 300 years for Acer mono, whereas that of Acer japonicum (understory species) was 74 years.

For the three species (Abies sachalinensis and two Acer spp.), spatial distribution of saplings and that of recruits during the 16 years were random irrespective of the presence/absence of canopy gaps $\left(\chi^{2}\right.$-test, $P>0.05$, Table 2$)$. This suggests that canopy gaps did not contribute to the recruitment of the three species. Spatial distribution of saplings and recruits of the three species (Abies sachalinensis and two Acer spp.) was negatively correlated with that of canopy trees of Abies sachalinensis and Acer mono, while it was positively correlated with that of canopy trees of Quercus crispula (Table 3, Fig. 5). The number of canopy trees of Acer japonicum and that of saplings of Quercus crispula were only 2 and 15 trees/ha respectively in 1998, and therefore we could not analyze their spatial distribution. The spatial distribution of recruits of the three species (Abies sachalinensis and two Acer spp.) was positively correlated with that of saplings of the same three species (Table 3; Fig. 5). However, the spatial association between Abies sachalinensis and Acer japonicum was unclear for saplings and for recruits. Effects of minor tree species other than the four dominant species on the spatial distribution of recruits of the three species (Abies sachalinensis and two Acer spp.) were probably negligible, because the number of canopy trees of these minor species was only 19 trees/ha in total.

The effects of intra- and interspecific competition on growth rate in DBH were examined by multiple linear regression analysis. Quercus crispula suppressed the growth rates of the three species (Abies sachalinensis and two Acer spp.) and that of itself (Fig. 6). This reflects the dominance of Quercus crispula in the upper canopy (Fig. 3). Acer mono and Acer japonicum co-occurred (Table 3), and the growth rate of Acer mono was reduced by Acer japonicum (Fig. 6). Negative or positive interactions were not detected for other combination of species.

\section{Discussion}

\subsection{Stand development}

In this forest, Quercus crispula dominated in the most upper layer and was older than the other species, but its regeneration was discontinuous. Sano (1997) showed a similar pattern in another Quercus crispula forest near our study site. Some researchers reported that Quercus crispula forms secondary forests by vegetative sprouting after large disturbances such as typhoon or after cutting (Kamitani, 1993; Ida and Nakagoshi, 1994; Namikawa et al., 1997). Therefore, it is likely that Quercus crispula regenerated after a large disturbance in this forest before the establishment of 
other species. In addition, density and basal area of the most species, except for Quercus crispula, increased during the census period, and canopy closure proceeded. Thus, it is suggested that this forest is still developing and that species composition and size structure of each species are not stable in time.

\subsection{Effects of Sasa on regeneration}

Mortality of trees taller than $2 \mathrm{~m}$ in this forest was $0.54 \% / \mathrm{yr}$. This is quite low, compared with other forests. Mortality of other deciduous broad-leaved forests in Japan ranges between 0.6-4.3\%/yr (Nakashizuka et al., 1992; Hara et al., 1995; Masaki et al., 1999; Umeki and Kikuzawa, 1999). In general, high density causes high mortality both at the individual tree and stand levels (Welden et al., 1991; Umeki and Kikuzawa, 1999). Umeki and Kikuzawa (1999) reported that the average density of trees larger than $5 \mathrm{~cm}$ in DBH was 724 trees/ha in 38 plots with various densities of dwarf bamboo Sasa in Hokkaido. In contrast, the density of our study site $>5 \mathrm{~cm}$ in $\mathrm{DBH}$ ) was only 492 trees/ha. There have been many reports that the presence of Sasa in the understory reduces the regeneration rate of trees (Nakashizuka and Numata, 1982; Nakashizuka, 1988; Taylor and Qin, 1988; Takahashi, 1994, 1997; Kudoh et al., 1999). In this forest, saplings and recruits of the three species (Abies sachalinensis and two Acer spp.) did not concentrate in canopy gaps. The density of Sasa increases in canopy gaps or under brighter conditions, resulting in reduced recruitment of trees (Sano, 1988; Takahashi, 1997). Therefore, the dense Sasa cover of this forest may have reduced the recruitment of trees, which also resulted in low mortality due to low density of trees.

\subsection{Pattern of recruitment and species coexistence}

The spatial distribution of saplings and recruits of the three species (Abies sachalinensis and two Acer spp.) was negatively correlated with that of canopy trees of Abies sachalinensis and Acer mono, but was positively correlated with that of canopy trees of Quercus crispula. These relationships are probably ascribed to abiotic factors such as light conditions rather than to species-specific biotic factors, because saplings and recruits of the three species (Abies sachalinensis and two Acer spp.) showed a relatively similar manner in spatial dispersion. Most of the canopy trees of Abies sachalinensis and Acer mono were shorter than those of overtopping Quercus crispula in this forest. Light intensity at the forest floor is progressively reduced when the crown base is near the ground level (Kikuzawa et al., 1988; Ishizuka and Kanazawa, 1989), because much light can penetrate into the forest floor from various directions when the crown base is high. It is expected that light intensity is lower under the lower-positioned crowns of Abies sachalinensis and Acer mono than under the higher-positioned crowns of Quercus crispula. Therefore, the saplings of the three species probably could not recruit under the crowns of Abies sachalinensis or Acer mono.

We detected only the competitive effect of Quercus crispula on the growth rate of all species and that of Acer japonicum on the growth rate of Acer mono. These patterns of intra- and interspecific competition correlate with their spatial patterns, i.e., the saplings and recruits of the three species (Abies sachalinensis and two Acer spp.) were found more under the crowns of Quercus crispula than under the crowns of their own canopy trees. However, the quite low mortality indicates that intra- and interspecific competition was not strong for trees taller than $2 \mathrm{~m}$ in this forest. Therefore, trees can grow and survive once over $2 \mathrm{~m}$ in trunk height. Several authors have reported that competitive effect on growth rate of adult trees (DBH $>5 \mathrm{~cm}$ or 
trunk height $>2 \mathrm{~m}$ in most studies) was small in other deciduous broad-leaved forests and conifer-hardwood mixed forests in Japan, and suggested that recruitment processes were more determinant for species coexistence than competition between adult trees (Hara et al., 1995; Kubota and Hara, 1995; Hiura and Fujiwara, 1999). The results of the present study are in accordance with those of previous studies, i.e., competitive effect on growth rate of adult trees was not large at this density and cannot be a major structuring force of the tree community. A possible reason for the weak competition is the low density of trees due to the dense Sasa cover in the forest floor. As a conclusion, our long-term study revealed that this forest is not in equilibrium in terms of species composition and size structure, and factors affecting recruitment processes (disturbance, crown stratification and Sasa in the forest floor) are more important for species coexistence than competition between trees taller than $2 \mathrm{~m}$.

\section{Acknowledgements}

We are grateful to Forest Research Station, Field Science Center for Northern Biosphere, Hokkaido University for providing the permanent-plot data. Our thanks are also due to K. Abe, K. Arikura, K. Homma, K. Ichikawa, Y. Ishikawa, A. Kamada, T. Kamiura, K. Namikawa, S. Okitsu, S. Okuyama, M. Takahata, T. Takanishi and H. Takahashi for data collection of this long-term study.

\section{References}

Abrams, M.D., Orwig, D.A., 1996. A 300-year history of disturbance and canopy recruitment for co-occurring white pine and hemlock on the Allegheny Plateau, USA. J. Ecol. 84, 353-363.

Bunyavejchewin, S., 1999. Structure and dynamics in seasonal dry evergreen forest in northeastern Thailand. J. Veg. Sci. 10, 787-792.

Canham, C.D., and Loucks, O.L., 1984. Catastrophic wind-throw in the presettlement forests of Wisconsin. Ecology 65, 803-809.

Duncan, R.P., 1991. Competition and the coexistence of species in a mixed podocarp stand. J. Ecol. 79, 1073-1084.

Duncan, R.P. 1993. Flood disturbance and the coexistence of species in a lowland podocarp forest, south Westland, New Zealand. J. Ecol. 81, 403-416.

Forcier, L.K., 1975. Reproductive strategies and the co-occurrence of climax tree species. Science 189, 808-810.

Fox, J.F., 1977. Alternation and coexistence of tree species. Am. Nat. 111, 69-89.

Hara, T., Nishimura, N., Yamamoto, S., 1995. Tree competition and species coexistence in a cool-temperate old-growth forest in southwestern Japan. J. Veg. Sci. 6, 565-574.

Hiura, T., Fujiwara, K., 1999. Density-dependence and co-existence of conifer and broad-leaved trees in a Japanese northern mixed forest. J. Veg. Sci. 10, 843-850.

Ida, H., Nakagoshi, N., 1994. Regeneration of a temperate deciduous forest in Sasa grassland: process of zonation of Fagus crenata forest-Quercus mongolica var. grosseserrata forest-Sasa grassland. Jpn. J. Ecol. 44, 271-281. (in Japanese)

Ishikawa, Y., Ito, K., 1989. The regeneration process in central Hokkaido, Japan. Vegetatio 79, 75-84.

Ishikawa, Y., Krestov, P.V., Namikawa, K., 1999. Disturbance history and tree establishment in old-growth Pinus koraiensis-hardwood forests in the Russian Far East. J. Veg. Sci. 10, 439-448.

Ishizuka, M., Kanazawa, Y., 1989. Growth process of Abies sachalinensis under Picea 
jezoenesis, Tilia japonica, and Acer mono in mixed coniferous-broadleaved forests of Hokkaido. J. Jpn. For. Soc. 71, 281-287. (in Japanese)

Iwao, S., 1977. Analysis of spatial association between two species based on the interspecies mean crowding. Res. Popul. Ecol. 18, 243-260.

Kamitani, T., 1993. Ecological studies on regeneration of beech (Fagus crenata Blume) coppice forests in heavy snowfall region. Mem. Fac. Agr. Niigata Univ. 30, 1-108. (in Japanese)

Kikuzawa, K., Asai, T., Mizui, N., 1988. Relative light intensity in thinned stands of Norway spruce. Trans. Meet. Hokkaido br. Jpn. For. Soc. 36, 118-120. (in Japanese)

Kira, T., 1949. Forest zone of Japan. Ringyogizyutu-kyokai, Tokyo. (in Japanese)

Kohyama, T., 1992. Size-structured multi-species model of rain forest trees. Funct. Ecol. 6, 206-212.

Kohyama, T., 1993. Size-structured tree populations in gap-dynamic forest: the forest architecture hypothesis for the stable coexistence of species. J. Ecol. 81, 131-143.

Kohyama, T., Suzuki, E., Hotta, M., 1994. Spatial distribution pattern of regenerative tree species in a footfill rain forest in west Sumatra. Tropics 4, 1-15.

Kubota, Y., Hara, T., 1995. Tree competition and species coexistence in a sub-boreal forest, northern Japan. Ann. Bot. 76, 503-512.

Kudoh, H., Kadomatsu, M., Noda, M., Akibayashi, Y., Natsume, S., Kaneko, K., 1999. Long-term observation on the growth of Sasa kurilensis regenerated after mass flowering and associated plants in northern Japan: a 31 year-observation. Res. Bull. Hokkaido Univ. For. 56, 30-40. (in Japanese)

Lorimer, C.G., 1977. The presettlement forest and natural disturbance cycle of northeastern Maine. Ecology 58, 139-148.

Manabe, T., Yamamoto, S., 1997. Spatial distribution of Eurya japonica in an old-growth evergreen broad-leaved forest, SW Japan. J. Veg. Sci. 8, 761-772.

Manokaran, N., Kochummen, K.M., 1987. Recruitment, growth and mortality of tree species in a lowland dipterocarp forest in Peninsular Malaysia. J. Trop. Ecol. 3, 315-330.

Masaki, T., Tanaka, H., Tanouchi, H., Sakai, T., Nakashizuka, T., 1999. Structure, dynamics and disturbance regime of temperate broad-leaved forests in Japan. J. Veg. Sci. 10, 805-814.

Nakashizuka, T., 1988. Regeneration of beech (Fagus crenata) after the simultaneous death of undergrowing dwarf bamboo (Sasa kurilensis). Ecol. Res. 3, 21-35.

Nakashizuka, T., 1991a. The importance of long-term studies of forest dynamics in large plots. Jpn. J. Ecol. 41, 45-53. (in Japanese)

Nakashizuka, T., 1991b. Population dynamics of coniferous and broad-leaved trees in a Japanese temperate mixed forest. J. Veg. Sci. 2, 413-418.

Nakashizuka, T., Numata, M., 1982. Regeneration process of climax beech forests. I. Structure of beech forest with the undergrowth of Sasa. Jpn. J. Ecol. 32, 57-67.

Nakashizuka, T., Iida, S., Tanaka, H., Shibata, M., Abe, S., Masaki, T., Niiyama, K., 1992. Community dynamics of Ogawa Forest Reserve, a species rich deciduous forest, central Japan. Vegetatio 103, 105-112.

Nakashizuka, T., Kohyama, T., 1995. The significance of the asymmetric effect of crowding for coexistence in a mixed temperate forest. J. Veg. Sci. 6, 509-516.

Namikawa, K., 1996. Stand dynamics during a 12 year period in an old-growth, cool temperate forest in northern Japan. Ecol. Res. 11, 23-33.

Namikawa, K., Ishikawa, Y., Sano, J., 1997. Stand dynamics during a 12-year period in a second-growth stand in a cool temperate forest in northern Japan. Ecol. Res. 12, 
277-287.

Ohsawa, M., 1995. Latitudinal composition of altitudinal changes in forest structure, leaf-type, and species richness in humid monsoon Asia. Vegetatio 121, 3-10.

Oliver, C.D., Stephens, E.P., 1977. Reconstruction of a mixed-species forest in central New England. Ecology 58, 562-572.

Osawa, A., 1992. Development of a mixed-conifer forest in Hokkaido, northern Japan, following a catastrophic windstorm: A "parallel" model of plant succession. In: Kelty, M.J., Larson, B.C., Oliver, C.D. (Eds.), The ecology and silviculture of mixed-species forests. Kluwer Academic Publ., Dordrechtpp, pp. 29-52.

Runkle, J.R., 1981. Gap regeneration in some old-growth forests of the eastern United States. Ecology 62, 1041-1051.

Sano, J., 1988. Studies on regeneration patterns in natural oak (Quercus mongolica var. grosseserrata) forests through community structure analysis. Res. Bull. Hokkaido Univ. For. 45, 221-266. (in Japanese)

Sano, J., 1997. Age and size distribution in a long-term forest dynamics. For. Ecol. Manage. 92, 39-44.

Sokal, R.R., Rohlf, F.J., 1981. Biometry. W. H. Freeman and Company, New York.

Takahashi, K., 1994. Effect of size structure, forest floor type and disturbance regime on tree species composition in a coniferous forest in Japan. J. Ecol. 82, 769-773.

Takahashi, K., 1997. Regeneration and coexistence of two subalpine conifer species in relation to dwarf bamboo in the understorey. J. Veg. Sci. 8, 529-536.

Takahashi, K., Kohyama, T., 1999. Size-structure dynamics of two conifers in relation to understorey dwarf bamboo: a simulation study. J. Veg. Sci. 10, 833-842.

Takahashi, K., Homma, K., Vetrova, V.P., Florenzev, S. Hara, T., 2001. Stand structure and regeneration patterns in a Betula platyphylla-Picea ajanensis forest in the central Kamchatka peninsula. J. Veg. Sci. (in press)

Tatewaki, M., 1958. Forest ecology of the islands of the North Pacific Ocean. J. Fac. Agr. Hokkaido Univ. 50, 371-486.

Taylor, A.H., Qin, Z., 1988. Regeneration patterns in old-growth Abies-Betula forests in the Wolong Natural Reserve, Sichuan, China. J. Ecol. 76, 1204-1218.

Tsuyuzaki, S., Haruki, M., 1996. Tree regeneration patterns on Mount Usu, northern Japan, since the 1977-1978 eruptions. Vegetatio 126, 191-198.

Umeki, K., Kikuzawa, K., 1999. Long-term growth dynamics of natural forests in Hokkaido, northern Japan. J. Veg. Sci. 10, 815-824.

Welden, C.W., Hewett, S.W., Hubbell, S.P., Foster, R.B., 1991. Sapling survival, growth, and recruitment: relationship to canopy height in a neotropical forest. Ecology 72 , $35-50$.

Whitney, G.G., 1990. The history and status of the hemlock-hardwood forests of the Allegheny Plateau. J. Ecol. 78, 443-458.

Woods, K. D., 1984. Patterns of tree replacement: canopy effects on understory pattern in hemlock-northern hardwood forests. Vegetatio 56, 87-107.

Woods, K.D., 2000a. Dynamics in late-successional hemlock-hardwood forests over three decades. Ecology 81, 110-126.

Woods, K.D., 2000b. Long-term change and spatial pattern in a late-successional hemlock-northern hardwood forest. J. Ecol. 88, 267-282.

Yamamoto, S., Nishimura, N., Matsui, K., 1995. Natural disturbance and tree species coexistence in an old-growth beech-dwarf bamboo forest, southwestern Japan. J. Veg. Sci. 6, 875-886. 


\section{Figure legends}

Fig. 1. Relationship between recruitment rate (\%/yr) during 1982-1998 and the observed maximum DBH for 10 component species in a 1-ha plot in a sub-boreal conifer-hardwood mixed forest, northern Japan. The observed recruitment rate and maximum DBH (listed in Table 1) were arcsine- and ln-transformed, respectively. Species abbreviations are the same as in Table 1.

Fig. 2. Frequency distributions of trunk diameter at breast height for the four dominant species in a 1-ha plot in a sub-boreal conifer-hardwood mixed forest, northern Japan, in 1998.

Fig. 3. Frequency distributions of tree height for the four dominant species in a 1-ha plot in a sub-boreal conifer-hardwood mixed forest, northern Japan, in 1998.

Fig. 4. Frequency distributions of tree age at breast height for the four dominant species larger than $6.0 \mathrm{~cm}$ in DBH in a 1-ha plot in a sub-boreal conifer-hardwood mixed forest, northern Japan, in 1998.

Fig. 5. Spatial dispersion of the four dominant species in a 1-ha plot in a sub-boreal conifer-hardwood mixed forest, northern Japan. Each square denotes a 20-m $\times 20-\mathrm{m}$ quadrat. Crosses, open circles, small and large solid circles represent recruits during 1982-1998, saplings (2.0-9.9 m tall), small canopy trees (10.0-19.9 m) and large canopy trees (over $20.0 \mathrm{~m}$ tall), respectively, in 1982.

Fig. 6. Results of multiple linear regression analysis for $G_{k}(t, x)$ function of four dominant species (Quercus crispula, Abies sachalinensis, Acer mono, Acer japonicum) in a sub-boreal conifer-hardwood mixed forest, northern Japan. An arrow from species $i$ to species $k$ indicates a negative competitive effect of species $i$ on species $k$ in the $G_{k}(t$, $x$ ) function, chosen by forward stepwise regression $(P<0.05)$, i.e., DBH growth rate of species $k$ is reduced by species $i$. Positive interaction was not observed. The ajusted- $R^{2}$ were $0.106(P<0.001, n=130)$ for Quercus crispula, $0.432(P<0.001, n=$ $100)$ for Abies sachalinensis, $0.169(P<0.001, n=135)$ for Acer mono and $0.261(P<$ $0.001, n=62)$ for Acer japonicum. Species are arranged according to their dominant vertical strata. 


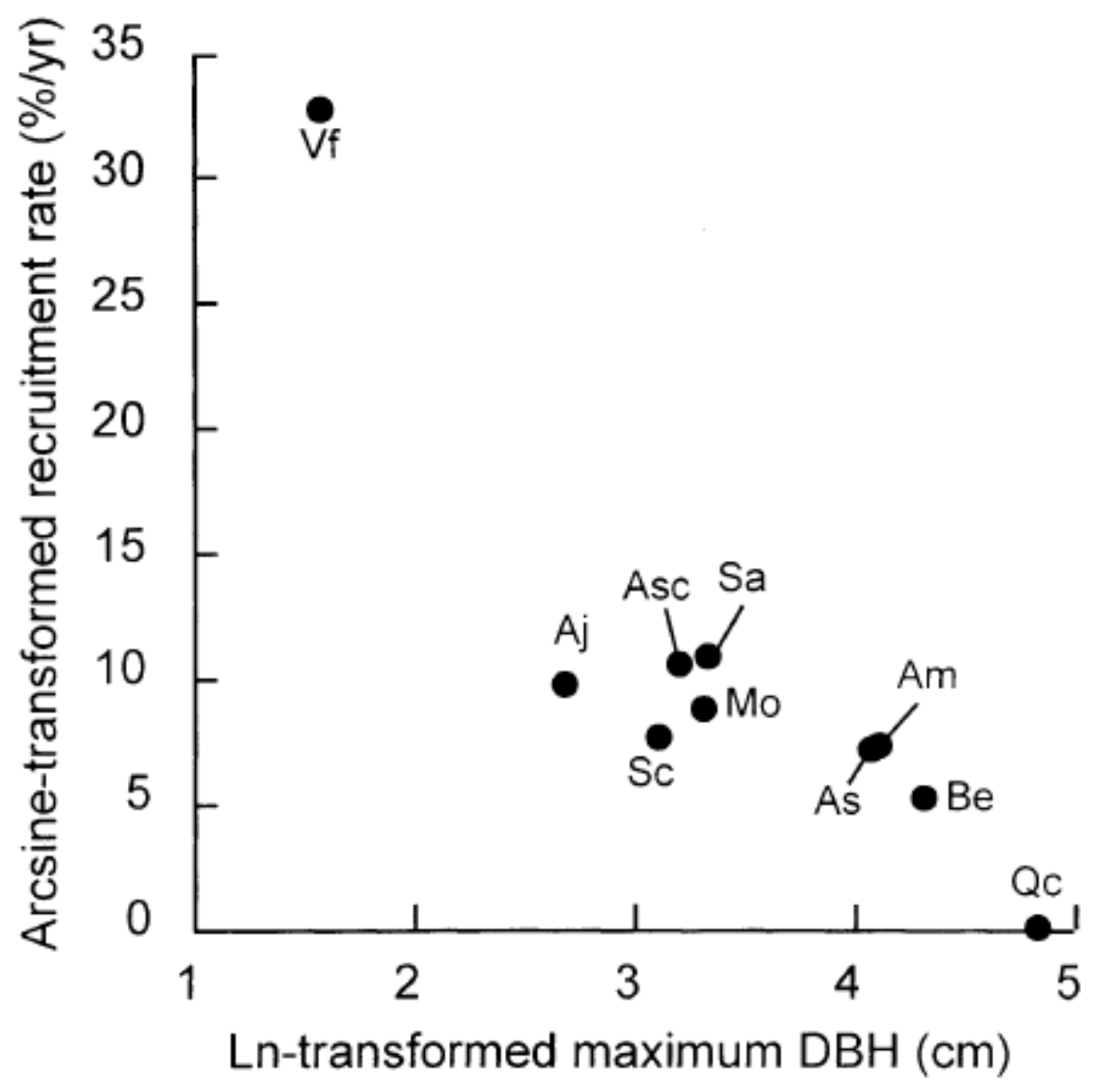

Fig. 1 
Takahashi et al. 14
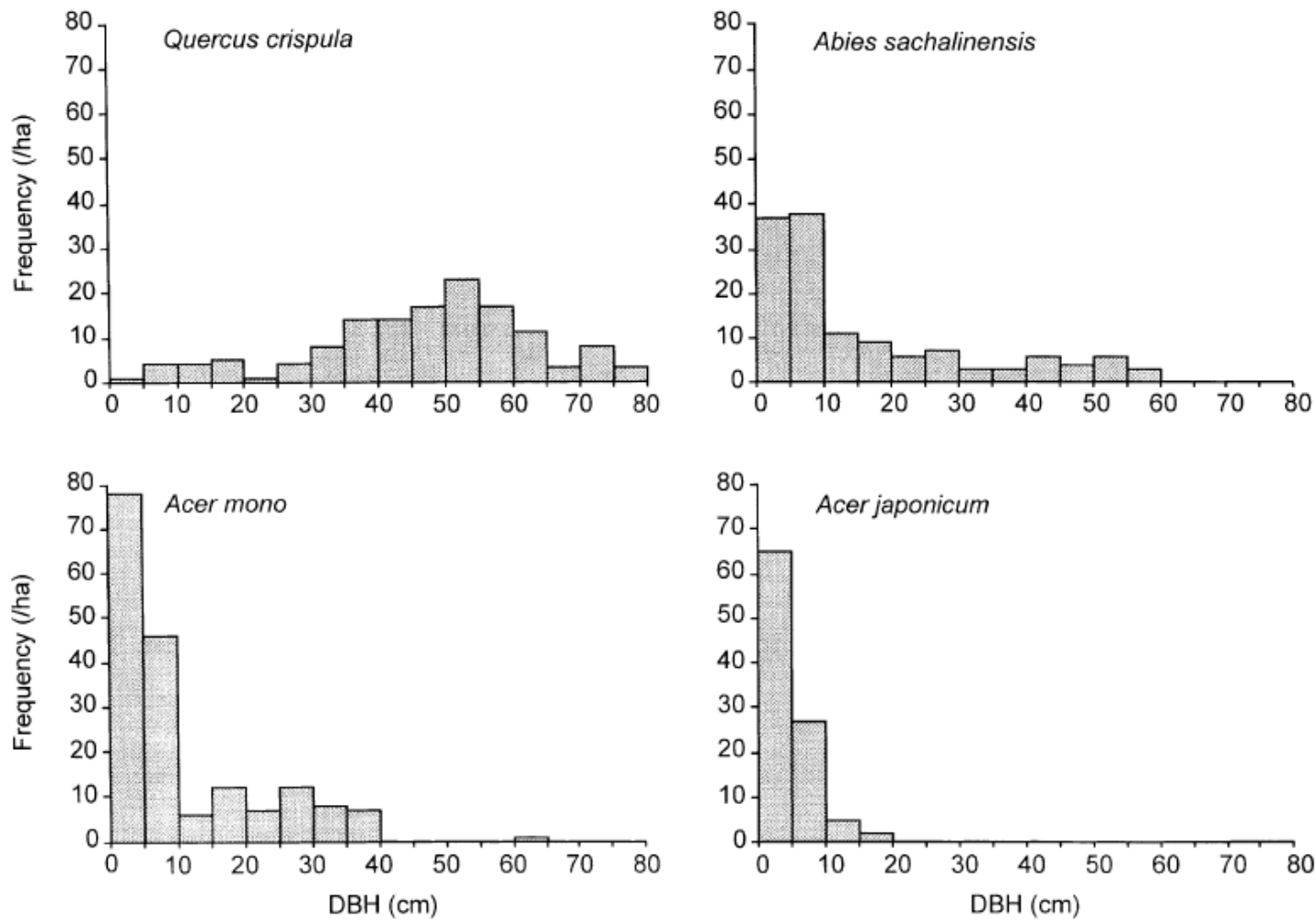

Fig. 2 
Takahashi et al. 15
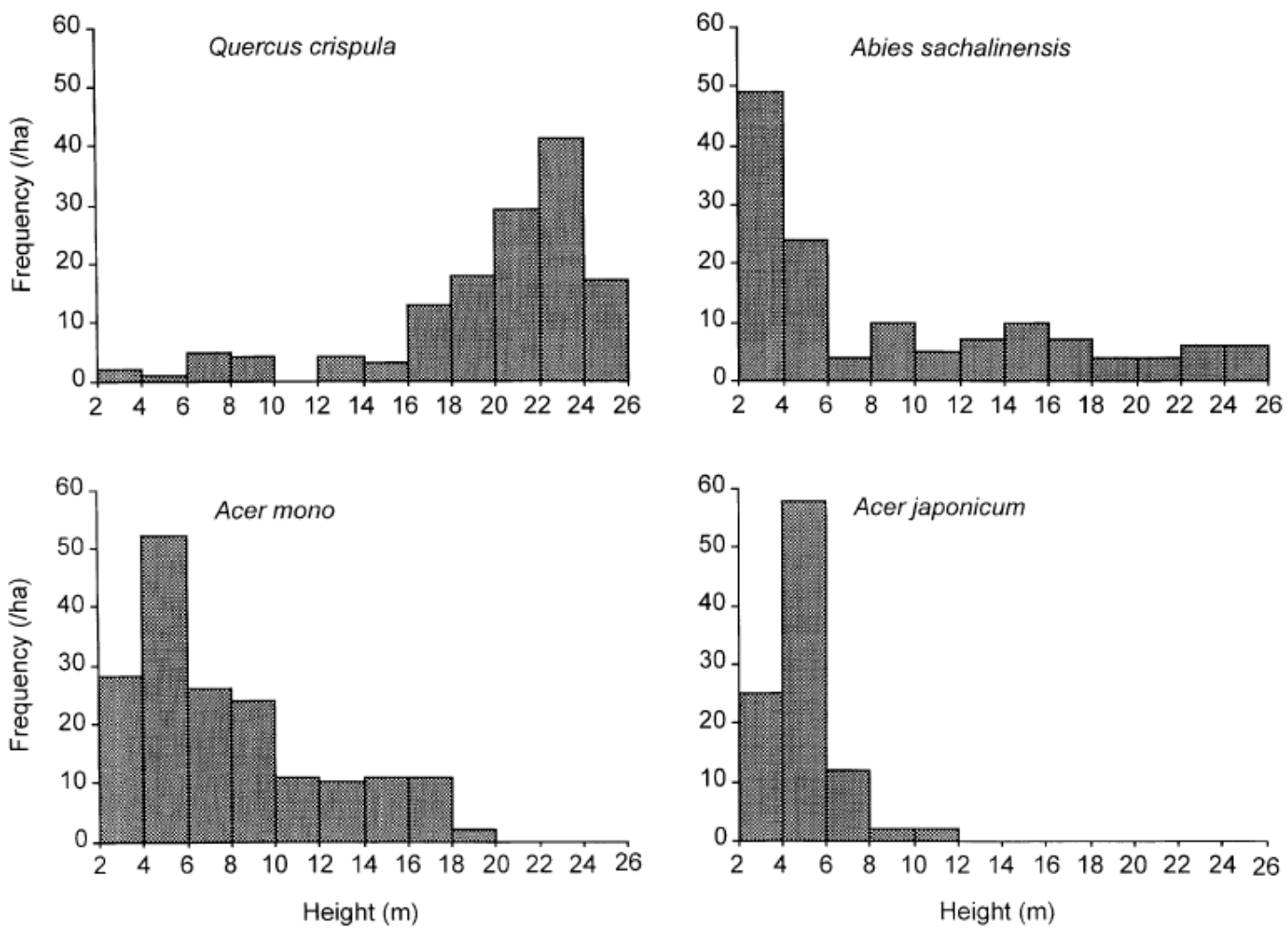

Fig. 3 

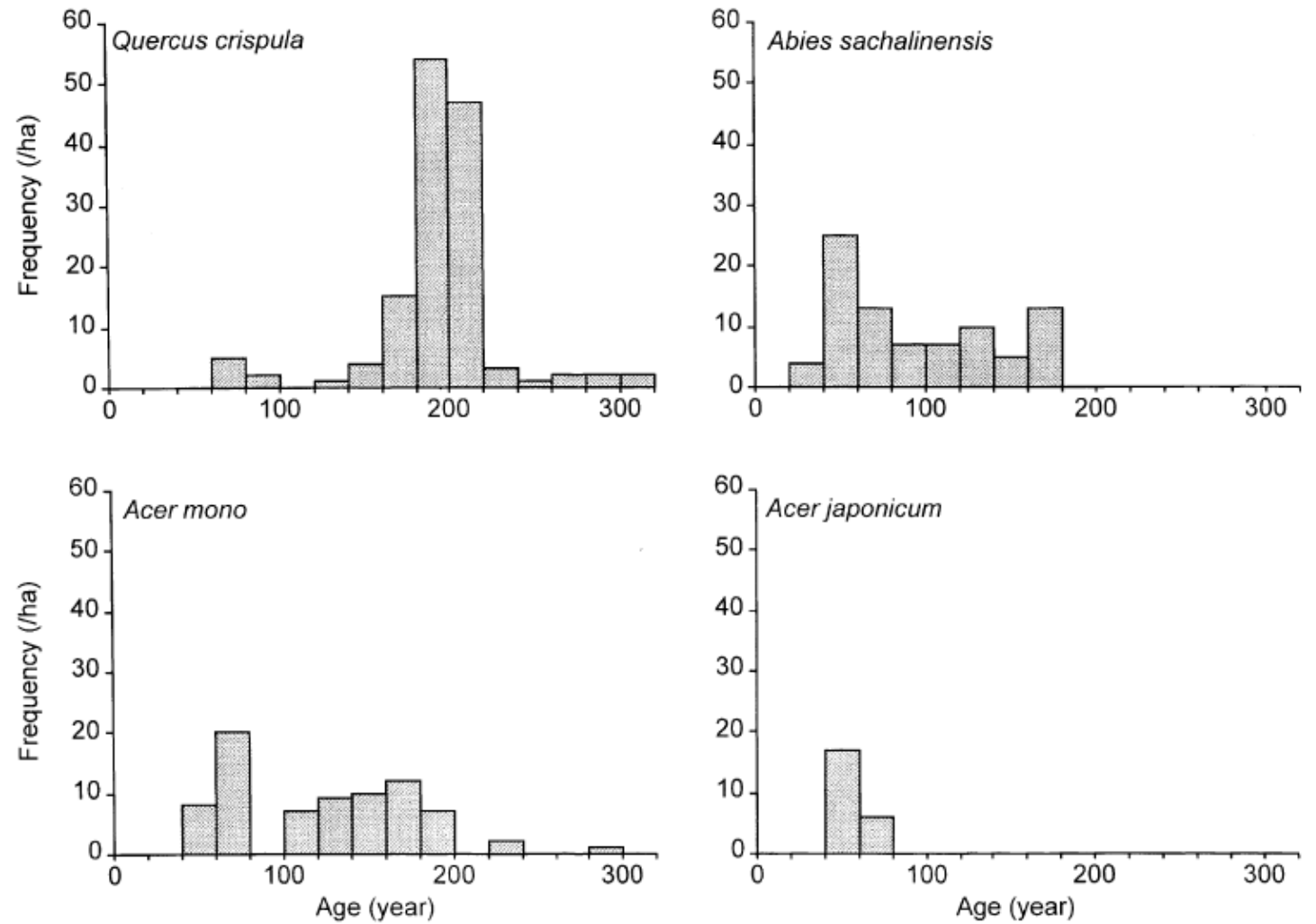

Fig. 4 
Acer japonicum

\begin{tabular}{|c|c|c|c|c|}
\hline$\circ \circ$ & $\begin{array}{cc}0 & 0 \\
& 0 \\
& \times \\
\end{array}$ & - $\quad 0$ & $8_{x} \cdot 0$ & $\circ$ \\
\hline 00 & $\begin{array}{r}\times \\
\circ \quad 8\end{array}$ & $\circ$ & $\begin{array}{c}\alpha^{x} \\
\times\end{array}$ & a \\
\hline$\circ$ & & 0 & o & $\circ \quad \circ$ \\
\hline & 8 & 0 & $x$ & \\
\hline & $e_{0}^{2}$ & $\alpha$ & $\times$ & \\
\hline
\end{tabular}

Abies sachalinensis

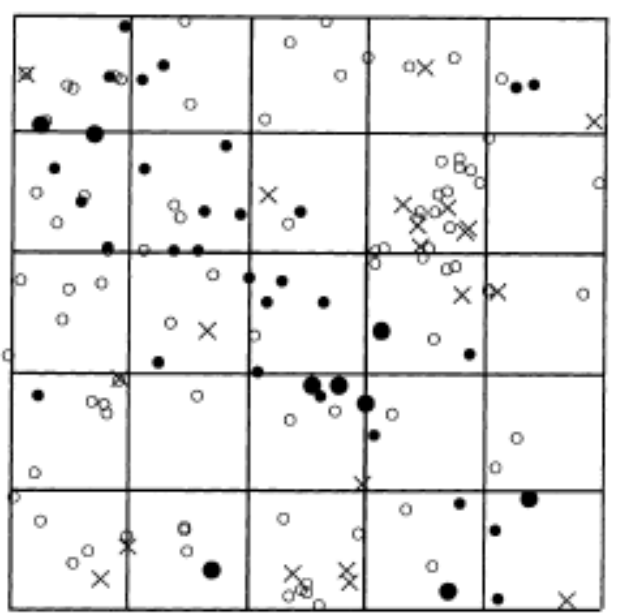

Acer mono

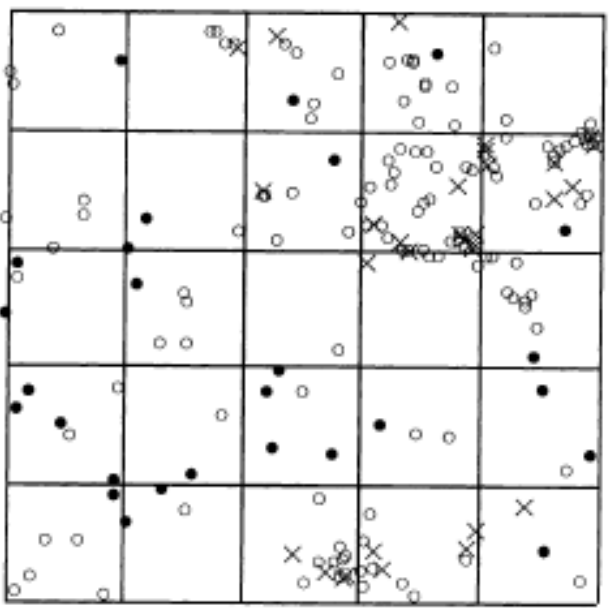

Quercus crispula

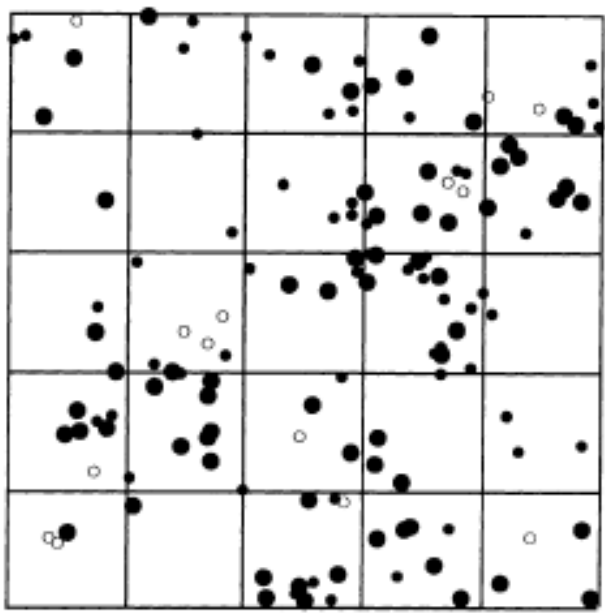

Fig. 5 


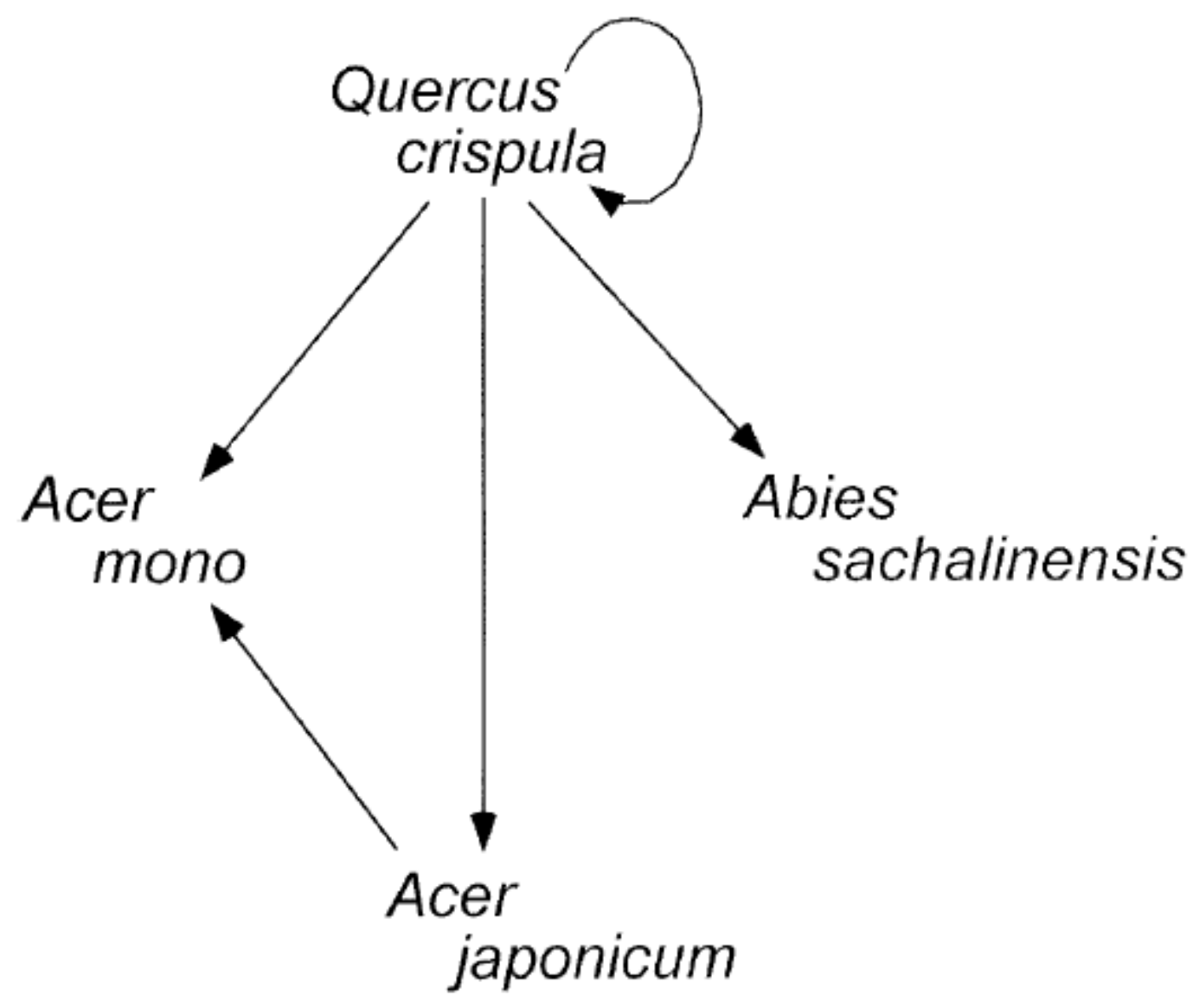

Fig. 6 
Table 1. Changes in basal area and density of trees (taller than $2 \mathrm{~m}$ ) between 1982 and 1998, and the observed maximum tree size of each species in 1998 in a 1-ha plot in a cool-temperate conifer-hardwood mixed forest, northern Japan. Only species with density $\geq 10$ trees/ha in 1998 are listed. Species are arranged by basal area in 1998.

\begin{tabular}{|c|c|c|c|c|c|c|c|c|c|c|c|}
\hline \multirow[b]{2}{*}{ Species } & \multicolumn{2}{|c|}{ Basal area $\left(\mathrm{m}^{2} / \mathrm{ha}\right)$} & \multicolumn{6}{|c|}{ Density (trees/ha) } & \multicolumn{2}{|c|}{ Maximum } & \multirow{2}{*}{$\begin{array}{c}\text { Species } \\
\text { abbre- } \\
\text { viation }\end{array}$} \\
\hline & 1982 & 1998 & 1982 & 1998 & Dead & $(\% / \mathrm{yr})$ & Recruit & $(\% / y r)$ & $\begin{array}{l}\text { (cm) } \\
\text { (cm }\end{array}$ & (m) & \\
\hline Quercus crispula & 24.63 & 27.60 & 140 & 137 & 3 & 0.13 & 0 & 0.00 & 127.6 & 24.5 & Qc \\
\hline Abies sachalinensis & 4.84 & 5.38 & 123 & 137 & 16 & 0.81 & 30 & 1.52 & 60.0 & 25.0 & As \\
\hline Acer mono & 3.22 & 3.37 & 153 & 178 & 13 & 0.53 & 38 & 1.55 & 62.0 & 19.0 & Am \\
\hline Betula ermaneii & 2.16 & 2.25 & 31 & 33 & 2 & 0.40 & 4 & 0.81 & 76.6 & 24.0 & $\mathrm{Be}$ \\
\hline Acanthopanax sciadophylloides & 0.39 & 0.47 & 50 & 56 & 8 & 1.00 & 14 & 1.75 & 22.9 & 16.5 & Asc \\
\hline Magnolia obovata & 0.23 & 0.30 & 30 & 38 & 3 & 0.63 & 11 & 2.29 & 28.0 & 17.0 & Mo \\
\hline Sorbus commixta & 0.14 & 0.27 & 19 & 26 & 3 & 0.99 & 10 & 3.29 & 25.1 & 14.0 & $\mathrm{Sc}$ \\
\hline Acer japonicum & 0.29 & 0.24 & 71 & 100 & 3 & 0.26 & 32 & 2.82 & 15.0 & 11.0 & $\mathrm{Aj}$ \\
\hline Sorbus alnifolia & 0.18 & 0.12 & 9 & 11 & 3 & 2.08 & 5 & 3.47 & 28.2 & 13.0 & $\mathrm{Sa}$ \\
\hline Viburnum furcatum & $<0.01$ & 0.01 & 3 & 17 & 0 & 0.00 & 14 & 29.17 & 4.9 & 3.9 & Vf \\
\hline Others & 0.72 & 0.78 & 22 & 25 & 5 & 1.42 & 8 & 2.27 & & & \\
\hline Total & 36.79 & 40.79 & 651 & 758 & 59 & 0.57 & 166 & 1.59 & & & \\
\hline
\end{tabular}


Table 2. Number of recruits (passing the minimum boundary of $2 \mathrm{~m}$ in height during 1982-1998) and saplings (2.0-9.9 $\mathrm{m}$ tall) in the gap grids and the non-gap grids of the 80-m $\times 80$-m quadrat in a 1-ha plot in a cool-temperate conifer-hardwood mixed forest in northern Japan. Data in 1982 and 1992 were used for saplings and canopy conditions, respectively (see text). Gap and non-gap grids occupied $23.4 \%$ and $76.6 \%$, respectively, in 1992. Degree of freedom is 1 for $\chi^{2}$ test. Species abbreviations are the same as in Table 1.

\begin{tabular}{lccc}
\hline & As & Am & Aj \\
& & & \\
\hline Recruits & 2 & 2 & 8 \\
$\quad$ Gap grids & 19 & 17 & 21 \\
$\quad$ Non-gap grids & 2.26 & 1.76 & 0.28 \\
$\chi^{2}$ statistics & & & \\
& & & 7 \\
Saplings & 12 & 10 & 44 \\
$\quad$ Gap grids & 46 & 63 & 2.66 \\
Non-gap grids & 0.24 & 3.83 & \\
$\chi^{2}$ statistics & & & \\
\end{tabular}


Table 3. Results of spatial correlation, using $\omega$ index, among canopy tree (taller than $10.0 \mathrm{~m}$ in trunk height), sapling (2.0-9.9 m) and recruit (during 1982-1998) of the four dominant species in a cool-temperate conifer-hardwood mixed forest, northern Japan. The quadrat size used in the analysis was $10-\mathrm{m} \times 10-\mathrm{m}$. Data in 1982 were used for saplings and canopy trees. Value in parentheses is the number of observations. Species abbreviations are the same as in Table 1.

\begin{tabular}{|c|c|c|c|c|c|c|c|c|c|}
\hline \multirow[b]{2}{*}{ Species $^{\dagger}$} & \multirow[b]{2}{*}{$n$} & \multicolumn{3}{|c|}{ Canopy tree } & \multicolumn{3}{|c|}{ Sapling } & \multicolumn{2}{|c|}{ Recruit } \\
\hline & & $\begin{array}{c}\text { Qc } \\
(125)\end{array}$ & $\begin{array}{l}\text { As } \\
(38)\end{array}$ & $\begin{array}{l}\text { Am } \\
(27)\end{array}$ & $\begin{array}{l}\text { As } \\
(85)\end{array}$ & $\begin{array}{c}\text { Am } \\
(126)\end{array}$ & $\begin{array}{c}\mathrm{Aj} \\
(70)\end{array}$ & $\begin{array}{l}\text { As } \\
(28)\end{array}$ & $\begin{array}{l}\text { Am } \\
(35)\end{array}$ \\
\hline \multicolumn{10}{|l|}{ Sapling } \\
\hline Abies sachalinensis & (85) & $0.27^{* *}$ & -0.26 & -0.30 & & & & & \\
\hline Acer mono & $(126)$ & $0.23^{*}$ & $-0.52^{*}$ & $-0.74^{* *}$ & $0.30^{* *}$ & & & & \\
\hline Acer japonicum & $(70)$ & $0.21^{*}$ & -0.21 & $-0.58^{*}$ & 0.07 & $0.25^{*}$ & & & \\
\hline \multicolumn{10}{|l|}{ Recruit } \\
\hline Abies sachalinensis & (28) & $0.34^{* *}$ & $-0.62^{*}$ & -0.21 & $0.51^{* * *}$ & $0.42^{* * *}$ & 0.05 & & \\
\hline Acer mono & (35) & $0.29^{*}$ & -0.47 & $-0.89^{*}$ & $0.39^{* *}$ & $0.69^{* * *}$ & $0.23^{*}$ & $0.47^{* * *}$ & \\
\hline Acer japonicum & (34) & 0.11 & -0.61 & $-0.89^{*}$ & 0.10 & 0.14 & $0.55^{* * *}$ & 0.03 & $0.32^{*}$ \\
\hline
\end{tabular}

*, $P<0.05 ; * *, P<0.01$; ***, $P<0.001$ by randomization test. 